\title{
FILOSOFAR O MORIR
}

\author{
Philosophize or Die \\ Abdiel Rodríguez Reyes \\ Universidad de Panamá \\ abdielarleyrodriguez@hotmail.com
}

Reseña de: Insausti, X., 2017. Filosofar o morir. La actualidad de la Teoría Crítica. Madrid: Plaza y Valdés, 122 Págs.

Xabier Francisco Insausti Ugarriza es un pensador crítico vasco, nació en el pequeño pueblo de Gopegi en la provincia de Álava a las faldas del Gorbea. Es doctor en Filosofía por la Ludwig - Maximilians Universität (Munich, Alemania) con la tesis Miguel de Unamunos und José Ortega y Gassets. Philosophie im Zusammenhang mit ihrer Hegel-Rezeption. Es profesor de Teoría del conocimiento en la Euskal Herriko Unibertsitatea (País Vasco, España). Ha traducido del alemán al euskera a: Adorno, Freud y Hegel; y del alemán al castellano a: Gerhad Vollmer y José Manzana. Ha sido profesor invitado en la Universidad Autónoma de Santo Domingo (República Dominicana), en la Universidad de El Salvador e investigador en el Centro de Estudios Vascos de la Universidad de Nevada, Reno (Estados Unidos). Entre muchas otras actividades internacionales. Ha coordinado, con otros/as colegas varios libros en Plaza y Valdés editores: Pensar la filosofía hoy (2011), Filosofía e inmanencia (2015) y en la Red de Pensamiento Crítico: Diálogos de pensamiento crítico (2008), Crítica, emancipación y construcción de la paz (2011) y Nuevos Diálogos de Pensamiento Crítico (2015). Actualmente está por concluir junto a José María Aguirre, el tercer y último tomo de las Obras completas de José Manzana Martínez de Marañon (19281978).

Leemos el libro de Insausti desde nuestro locus, es decir, desde la periferia poscolonial. Poniendo énfasis en los aspectos que nos interpelan. En síntesis, el libro es un balde de agua helada ante la anestesia colectiva. Tenía un título inicial un tanto más atractivo y dialéctico, el Nuevo vuelo del búho, que el binarismo: Filosofar-morir unido por una conjunción disyuntiva, el cual indica que debemos tomar partida para no sucumbir. Filosofar o morir, como el subtítulo nos indica, busca actualizar la Teoría Crítica. Mientras muchos «intelectuales», académicos, escritores y «pensadores»se pliegan al laissez faire y reproducen lo políticamente correcto, Insausti se atreve a ir a contrapelo.

El libro está compuesto por una Introducción (pp. 9-16), tres partes: 1- Intelectuales y pensadores críticos (pp. 17-38), 2 - La filosofía y la recuperación del sujeto dañado (pp. 39-80), 3- Política (pp. 81-112), un A modo de conclusión (105-108) y un anexo: Entrevista a Xabier Insausti (109-112), realizada en un rotativo panameño por Luis 
Pulido Ritter. Pese a algunos errores de dedo, el texto es fluido y permite una lectura fecunda.

En la Introducción señala que, «la filosofía necesita dar un paso atrás, volver a repensarse radicalmente» (p. 11), ante la «chapuza política» que hace confundir todo, en donde lo malo parece bueno, y lo bueno malo. Invertir el mundo pasa obligatoriamente por la crítica sin tregua al capitalismo desde las trincheras de la Teoría Crítica. Así, la Filosofía es un «medio de resistencia» ante los vejámenes del sistema que nos enajena y oprime, el pensador crítico es el aguafiestas en la sociedad del espectáculo (Guy Debord), donde los títeres tienen sueldos y los titiriteros están tras las transnacionales y gobiernos moviéndolo todo. El acto está montado, ahora corresponde -siguiendo a Horkheimer- "la crítica de lo que hay», esa es la función social de la Filosofía que quiere rescatar nuestro autor.

Alemania, España y Francia son los países que compara para diferenciar lo que es un intelectual de un pensador crítico. Estos países, guardando las proporciones tienen sus analogías. Nuestro autor, siguiendo la tradición hegeliana trabaja sobre conceptos, o mejor dicho, en la Filosofía (al menos para Hegel y Adorno), el trabajo crítico del concepto es fundamental. Así, ciertos conceptos tienen cargas tanto conservadoras como revolucionarias. El intelectual se ampara en conceptos abstractos, en cambio, el pensador crítico se foguea a favor de la justicia y las contradicciones concretas del sistema. Mientras que el intelectual se pliega al sistema, el pensador crítico lo cuestiona radicalmente. Mientras que el intelectual vive normalizado en una época de cambios para quedar igual, el pensador crítico piensa en un cambio de época. Mientras el intelectual se acomoda a la opinión pública, el pensador crítico incomoda a la opinión pública. El intelectual es el que normaliza el sentido común y apacigua las divergencias, el pensador crítico cuestiona el trasfondo que hace posible toda injusticia en las sociedades liberal-demócratas, mientras que, el intelectual las tiene como único horizonte posible.

El segundo capítulo, La filosofía y la recuperación del sujeto dañado, es el más denso. Por un lado, está el diagnóstico de un pensador crítico del contexto europeo de la Filosofía que, según él ha capitulado, cuando dice: «La filosofía desde entonces [de los años treinta del siglo XIX] ha perdido su relación con la realidad» (p.40); y por el otro, el intento de recuperar el sentido crítico de la primera generación de la Escuela de Frankfurt, en especial Adorno y Horkheimer. Nuestro autor se despliega en esa tradición haciendo un puente con el pensamiento crítico francés, a tal punto que, las dos propuestas que plantea en el tercer capítulo, son de dos franceses (Badiou y Piketty). Es de singular importancia ver el desplazamiento de la Teoría Crítica que propone nuestro autor. Esta va desde Hegel, por supuesto, a Alain Badiou, pasando por obras pendulares como Dialéctica de la ilustración de Adorno y Horkheimer, y Crítica de la razón instrumental de éste último.

La Política es el tercer y último capítulo. El libro tiene tres momentos, y el tercero es a modo de síntesis. El tema espinoso es el «reconocimiento» y la «autoconciencia» que trata Hegel en el tan aguerrido cuarto capítulo de la Fenomenología del espíritu. Señala Insausti: "Las autoconciencias se enfrentan por el reconocimiento; reconocerse mutuamente exige demostrar que se es distinto, es decir, demostrar su valor (su valía) frente a otras autoconciencias [...] Solo por medio del reconocimiento la autocon- 
ciencia se hace real» (p. 83). Susan Buck-Morss liga esto con la Revolución Haitiana. $\mathrm{Si}$ atamos los cabos, y tenemos en mente el relato de CLR James veremos la realización concreta de dicha bifurcación o cómo el pensamiento de Hegel emerge de contradicciones concretas que encontraron su punto más álgido cuando los esclavos por sí mismos alcanzaron su libertad.

Las propuestas que nos brinda en este tercer y último capítulo son: la de Piketty que se sintetiza a un mega impuesto a los mil millonarios. Luego de Piketty estudiar la evolución de las desigualdades en un arco de tiemplo amplio y desvelar con un aparato estadístico abundante la realidad que no queremos ver, pero está allí: el problema de la distribución de las riquezas, cómo se heredan las fortunas y perpetuán las miserias. El libro recoge oportunamente las críticas de David Harvey a Piketty. Y, la otra, La hipótesis comunista de Badiou, que desarrolló junto a Slavoj Zizek. El concepto comunismo está proscrito, usarlo es como invocar un fantasma como diría Marx y Engels -en el Manifiesto Comunista- e inmediatamente todos se unen para atacarlo. La hipótesis comunista es lo nuevo, puede ponérsele el nombre de emancipación, igualitarismo u otros, la praxis revolucionaria confirmará la validez y factibilidad de la misma. Lo viejo, en cambio, es el capitalismo que, con sus instituciones supuestamente democráticas no han resuelto nada y han empeorado todo.

En el anexo, ya mencionado, recapituló estos puntos. Enfatiza que la Filosofía necesita reengancharse con la realidad para recuperar a ese sujeto que ha quedado sumergido en el fetiche del capitalismo. A fin de cuentas, me hubiese gustado ver un diálogo -más allá de las menciones- con Dussel, Hinkelammert y Echeverría, pero lo entendemos, el contexto inmediato de nuestro autor es el Estado Español y Europa. La necesidad de actualizar la Teoría Crítica nos invita a re-pensar todo, en esa dirección transitan trabajos como Filosofar o morir. La actualidad de la Teoría Crítica, y de Axel Honneth La idea del socialismo. Una tentativa de actualización. Estos pensadores críticos nos preparan el terreno para ararlo con la potentia de las ideas. Esperemos que el búho pueda alzar el vuelo.

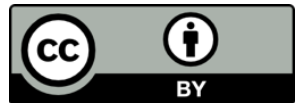

